\title{
Metrological traceability for the analysis of environmental pollutants in the atmosphere
}

\author{
Francesca Rolle, Enrica Pessana, Michela Sega \\ Istituto Nazionale di Ricerca Metrologica (INRiM), Strada delle Cacce 91, 10135 Torino, Italy
}

\begin{abstract}
The importance of carrying out accurate and reliable measurements is a fundamental topic in many different fields, in particular for the safeguard of the environment and the climatic conditions of the planet. This is the basis for the planning of correct actions to prevent environmental damages and potential harmful effects for the health of the human beings. The application of metrology to chemical monitoring can assure the reliability of measurement results.

At the Istituto Nazionale di Ricerca Metrologica (INRiM), the Italian Metrology Institute, different activities are carried out for the analysis of gaseous and organic pollutants in the atmosphere. This paper deals with some examples of such activities.

For gaseous pollutants primary gravimetric mixtures are produced for the calibration of the instrumentation devoted to the analysis of carbon dioxide $\left(\mathrm{CO}_{2}\right)$ and nitrogen oxides $\left(\mathrm{NO}_{\mathrm{x}}\right)$, with the aim of assuring traceability to the measurements of $\mathrm{CO}_{2}$ at ambient level and at the vehicles emission level, and of $\mathrm{NO}_{\mathrm{x}}$ at ambient level. On the other hand, research is carried out in the field of organic micropollutants, in particular regarding the establishment of metrological traceability for the atmospheric concentrations of Polycyclic Aromatic Hydrocarbons (PAHs) adsorbed on particulate matter (PM).
\end{abstract}

\section{Section: TECHNICAL NOTE}

Keywords: metrological traceability; environmental pollution; primary gaseous mixtures; polycyclic aromatic hydrocarbons

Citation: Francesca Rolle, Enrica Pessana, Michela Sega, Metrological traceability for the analysis of environmental pollutants in the atmosphere, Acta IMEKO, vol. 4, no. 4, article 12, December 2015, identifier: IMEKO-ACTA-04 (2015)-04-12

Editor: Paolo Carbone, University of Perugia, Italy

Received: September 30, 2014; In final form November 6, 2015; Published December 2015

Copyright: (C) 2015 IMEKO. This is an open-access article distributed under the terms of the Creative Commons Attribution 3.0 License, which permits unrestricted use, distribution, and reproduction in any medium, provided the original author and source are credited

Corresponding author: Francesca Rolle, e-mail: f.rolle@inrim.it

\section{INTRODUCTION}

The importance of carrying out accurate and reliable measurements is a fundamental topic in many different fields, in particular for the safeguard of the environment and the climatic conditions of the planet. This is the basis for the planning of correct actions to prevent environmental damages and potential harmful effects for the health of the human beings and biota. In this framework, the application of metrology to chemical monitoring can assure the reliability of measurement results, in particular for the analysis of pollutants in different environmental sectors. Metrological traceability of measurement results is a fundamental feature in every measurement field but is crucial when dealing with the environmental chemistry. In this field, the application of metrological concepts is not straightforward, as the analytes are usually present at very low concentrations (even in trace) and the sample matrix can generate interferences during the instrumental identification and quantification of the analytes of interest.

At the Istituto Nazionale di Ricerca Metrologica (INRiM), the Italian Metrology Institute, different activities are carried out for the analysis of gaseous and organic pollutants in the atmosphere. This paper deals with some examples of such activities.

On one hand, for gaseous pollutants, an important activity concerns the analysis of two species, carbon dioxide $\left(\mathrm{CO}_{2}\right)$ and nitrogen oxides $\left(\mathrm{NO}_{\mathrm{x}}\right)$, the former having great relevance for the greenhouse effect and the latter for the photochemical pollution in urban areas. At INRiM primary gravimetric mixtures are produced for the calibration of the instrumentation devoted to the analysis of these gases, with the aim of assuring metrological traceability to the measurements of $\mathrm{CO}_{2}$ at ambient level and at the vehicles emission level, and of $\mathrm{NO}_{\mathrm{x}}$ at ambient level. 
On the other hand, research is carried out in the field of organic micropollutants, in particular regarding the establishment of metrological traceability for the atmospheric concentrations of Polycyclic Aromatic Hydrocarbons (PAHs) adsorbed on particulate matter (PM). A suitable metrological procedure was developed for the extraction and determination of the priority PAHs, as defined by the United States Environmental Protection Agency (US EPA), on PM sampled from the air of Torino, Italy.

In Section 2, some remarks on the activity carried out for gas analysis are given. Section 3 is focused on organic micropollutant analysis.

\section{ANALYSIS OF GASEOUS ENVIRONMENTAL POLLUTANTS}

\subsection{INRIM ACTIVITY}

At INRiM, reference gas mixtures of carbon dioxide $\left(\mathrm{CO}_{2}\right)$ and nitrogen oxides $\left(\mathrm{NO}_{\mathrm{X}}\right)$ in the $\mu \mathrm{mol} / \mathrm{mol}$ range are realised by gravimetry, which is a primary method, described in the International Standard ISO 6142-1 [1].

Such primary mixtures are validated by using different analytical techniques: Non-Dispersive Infrared Spectroscopy (NDIR) for $\mathrm{CO}_{2}$, chemiluminescence analysis and Fourier transform infrared spectroscopy (FTIR) for $\mathrm{NO}_{\mathrm{x}}$.

Stability studies of the prepared mixtures are carried out for their possible use as certified reference materials (CRMs) for instrumental calibration.

A fundamental part of the work is devoted to the measurement uncertainty evaluation and to the study of the matrix effects on the analytical response.

\subsection{Carbon dioxide and nitrogen oxides}

$\mathrm{CO}_{2}$ is the primary greenhouse gas emitted through human activities and is naturally present in the atmosphere as part of the Earth's carbon cycle.

Human activities are altering the carbon cycle, both by adding more $\mathrm{CO}_{2}$ to the atmosphere and by influencing the ability of natural sinks, like forests, to remove $\mathrm{CO}_{2}$ from the atmosphere. The main sources of $\mathrm{CO}_{2}$ emissions are power plants, transportation, industry [2] and the most effective way to lower $\mathrm{CO}_{2}$ levels in atmosphere is to reduce its emissions and fossil fuel consumption.

$\mathrm{NO}_{\mathrm{x}}$ indicates the sum of nitric oxide (NO) and nitrogen dioxide $\left(\mathrm{NO}_{2}\right)$. NO generates from high temperature combustion processes (e.g in motor vehicles) while $\mathrm{NO}_{2}$ generates from $\mathrm{NO}$ by means of photochemical reactions.

$\mathrm{NO}_{\mathrm{x}}$ can be responsible for pulmonary diseases (e.g. asthma, bronchitis) for long periods of exposure at low concentrations. In the troposphere, they are classified as secondary pollutants and participate in the photochemical pollution cycle and in the acidic rains formation. In addition, NO has a large influence on both ozone and on the hydroxyl radical.

The sum of many oxidised nitrogen species, both organic and inorganic, is referred to as $\mathrm{NO}_{\mathrm{y}}$, excluding nitrous oxide $\left(\mathrm{N}_{2} \mathrm{O}\right)$, ammonia $\left(\mathrm{NH}_{3}\right)$, acetonitrile (ACN) and hydrocyanic acid ( $\mathrm{HCN})$.

The official method for $\mathrm{NO}_{\mathrm{x}}$ monitoring is the chemiluminescence analysis, as prescribed in the EN 14211 [3].

\subsection{Primary method for the preparation of gaseous reference materials}

At INRiM, primary gravimetric mixtures are prepared by using a validated procedure. The cylinders are previously conditioned by evacuating and heating them, then filling them with the matrix gas. This process is repeated at least 3 times. The preparation procedure of the mixtures is articulated into three steps: the empty cylinder is weighed and then filled with the analyte gas and the matrix gas. Each step is followed by a precision weighing, in order to determine the exact amount of gas introduced in the cylinder. The precision weighing is carried out by comparing the cylinder with a reference one following a double substitution scheme, to take into account also the contribution of the buoyancy effect.

\subsection{Results}

Recent activities carried out at INRiM concerned the realisation of $\mathrm{NO}_{2}$ primary mixtures in synthetic air at few $\mu \mathrm{mol} / \mathrm{mol}\left(8-12 \mu \mathrm{mol} / \mathrm{mol}\right.$ range), the realisation of $\mathrm{NO}_{2}$ mixtures with different $\mathrm{O}_{2}$ concentrations, for the evaluation of matrix effects and of $\mathrm{NO}$ mixtures in nitrogen at 500 $\mathrm{nmol} / \mathrm{mol}$.

Chemiluminescence and FTIR analysers were calibrated between 5 and $15 \mu \mathrm{mol} / \mathrm{mol}$ of $\mathrm{NO}_{2}$ in synthetic air and between 300 and $700 \mathrm{nmol} / \mathrm{mol}$ for $\mathrm{NO}$ (chemiluminescence) for the validation of these mixtures.

$\mathrm{CO}_{2}$ mixtures were prepared at ambient level (around 400 $\mu \mathrm{mol} / \mathrm{mol}$ ) and at the vehicle emission levels (11-14\%) and analysed by means of Non-dispersive Infrared Spectroscopy (NDIR).

Chemiluminescence analysis was thought to be a very selective technique for $\mathrm{NO}_{\mathrm{x}}$, but in recent years it was observed that this technique can give unsatisfactory response due to the interferences of $\mathrm{NO}_{y}$ species. For this reason, at INRiM, the chemiluminescence analysis is compared with FTIR analysis, which is less influenced by the interferences of other nitrogen species. At the moment, improvements are under investigation also to reduce interferences of environmental parameters (e.g. ambient temperature, relative humidity, air components) which can influence the FTIR analysis.

\section{ORGANIC MICROPOLLUTANTS ANALYSIS: POLYCYCLIC AROMATIC HYDROCARBONS (PAHS)}

PAHs are a class of organic micropollutants which are present in all the environmental compartments, i.e. soil, water, air and also in food. The latter represents the major source on intake for living beings. In addition, a relevant way of exposure is airborne particulate matter (PM), as PAHs can adsorb on PM particles and be carried into the respiratory system, even reaching the alveolar region of the lungs. Fine and ultrafine PM are important sources of urban pollution and are potentially responsible for several pathologies (mainly cardiovascular and respiratory). They may lead to harmful effects both for the direct action of the particles (i.e. inflammatory processes) and the action of many pollutants adsorbed on it (e.g. PAHs, heavy metals).

PAHs are a class of organic micropollutants of great concern for their fallouts on human health. Indeed scientific evidences showed that some PAHs may have carcinogenic effects. In particular the most harmful of them is benzo[a]pyrene $(\mathrm{BaP})$, which was classified as carcinogenic agent to humans (Group 1) by the International Agency for Research on Cancer (IARC) [4]. The European regulations prescribed the monitoring of this pollutant in ambient air and a target value of concentration in air of $1 \mathrm{ng} / \mathrm{m}^{3}$, for the total content in the $\mathrm{PM}_{10}$ fraction averaged over a calendar year is fixed [5]. 
In this framework, the use of reliable analytical methods for the determination of PAHs levels in the environment is necessary and the guarantee of accurate and comparable analytical results is fundamental to support the planning of preventive actions for the reduction of PM levels and emissions in atmosphere.

\subsection{INRiM method for the analysis of priority PAHs}

At INRiM a procedure for the quantification of $\mathrm{BaP}$ in ambient air was developed [6], starting from the guidelines given in the European standard method EN 15549 [7] which describes a methodology for the determination of $\mathrm{BaP}$ in ambient air adsorbed on PM and can be used in the framework of the European Directive related to air quality [8].

The developed method was extended to the $16 \mathrm{PAHs}$ classified as priority pollutants from US EPA and other PAHs having toxicological relevance. The procedure was applied to samples of total suspended particles (TSP) sampled in Torino. and was validated in all its steps, by evaluating different parameters among which the recovery efficiency, the limit of detection (LOD) and the limit of quantification (LOQ).

In our method, a classical extraction technique - Soxhlet extraction [9] - was chosen and the quantification was performed by means of gas chromatography coupled with mass spectrometry (GC-MS).

Sampling campaigns were carried out in different seasons to evaluate the concentration profiles of $\mathrm{PAHs}$ during the year. The PM was collected by means of a low volume sampler with a sampling head for TSP, using glass fibre filters as sampling media. The filters were weighed before and after the sampling to determine the real masses of sampled PM. In addition, the same procedure was used for the determination of the final volumes of the extracts, which were calculated from the weighed masses of each extract, taking into account the density of the extraction solvent. In this way, we could assure metrological traceability to the masses of PAHs in the sample extracts as they were gravimetrically determined by comparison with calibrated mass standards.

The metrological traceability of the quantification step was assured by calibrating the GC-MS with a set of reference standard solutions prepared by gravimetric dilution of a suitable CRM - NIST SRM 2260a - which contains 36 aromatic hydrocarbons in toluene.

The recovery efficiency ranges from 70 to $100 \%$ for the heavier PAHs (having more than 4 benzene rings) while for small PAHs (2-3 rings) the recovery efficiencies were generally not satisfactory, probably because these analytes are very volatile and can be lost during the extraction step.

The regulation [7] fixes a LOD value only for $\mathrm{BaP}$ (lower than $\left.0.04 \mathrm{ng} / \mathrm{m}^{3}\right)$. The LOD of our internal method was evaluated between 0.01 and $0.04 \mathrm{ng} / \mathrm{m}^{3}$ for all the PAHs, hence in agreement with the regulation. The only exception was phenanthrene with a LOD of $0.06 \mathrm{ng} / \mathrm{m}^{3}$. LOQ was calculated as 10 times the standard deviation of the repeated analyses of the blanks.

\subsection{Results and discussion}

The results obtained for PAHs analysis were in accordance with the provisioned seasonal trends. The concentrations measured in PM sampled in spring are below the target value of $1 \mathrm{ng} / \mathrm{m}^{3}$ fixed for $\mathrm{BaP}$ and are not very high compared with the results of samples collected in winter. The measured concentrations highlight the increasing trend of PAHs in atmosphere from spring to winter. These is a typical seasonal trend for PAHs, characterized by a lowering of their levels during spring and summer, mainly for the reduction of the emissions, the changing of the meteorological conditions and the increase of the ambient temperatures. During winter, the major emissions in urban centres come from the domestic heating plants and the vehicular outputs. In addition, the lowering of the mixing height in atmosphere forces the pollutants to persist longer in the lower troposphere while the colder temperatures can improve the repartition from vapour phase onto PM particles also for small PAHs, because their vapour pressure is strongly reduced by the decrease of the ambient temperatures.

$\mathrm{BaP}$ concentrations measured in winter samples exceeded the target value of $1 \mathrm{ng} / \mathrm{m}^{3}$. These results confirm the abundance of $\mathrm{BaP}$ and of the other PAHs in urban PM and, consequently, highlight the need of resolving actions for the reduction of PAHs inlets in atmosphere.

In addition, the results show that the ratios of the PAHs are almost constant in samples of different periods of the year and the repartition of PAHs between vapour and particulate phases is not affected by seasonal changes, but depends on the physico-chemical properties of PAHs and on the sources of emission. However, for particulate sampled during some rainy days a lowering of the PAHs level was observed. This is an example of the effects of the meteorological conditions on PM and PAHs levels in the troposphere. Favourable weather conditions can help the deposition of PM particles to the ground, consequently reducing the measured PAHs concentrations.

\section{CONCLUSIONS}

The metrological approach followed at INRiM for the analysis of gaseous and organic pollutants has very important fallouts on these fields of environmental measurements, in particular for the significance of the considered analytes. The aim of the work conducted at INRiM is in particular the establishment of correct metrological traceability chains for all the analytes considered.

Further developments for the preparation of gaseous reference materials concern the use of another primary method for the preparation of reference gas mixtures, namely the dynamic dilution technique. This method has the advantage of preparing primary mixtures prior to the use, hence it is suitable for unstable and reactive molecules and for low concentration levels.

In the field of organic analysis, improvements are foreseen in order to give traceability to the PM sampling step and performing sampling campaigns of PM, as requested by the European regulation, extending the research activity also to different analytes of environmental and toxicological interest.

\section{REFERENCES}

[1] International Standard ISO 6142-1:2015 "Gas analysis -Preparation of calibration gas mixtures -- Part 1: Gravimetric method for Class I mixtures"

[2] http://www3.epa.gov/climatechange/ghgemissions/sources.htm $\underline{1}$

[3] EN 14211:2012 “Ambient air. Standard method for the measurement of the concentration of nitrogen dioxide and nitrogen monoxide by chemiluminescence"

[4] http://monographs.iarc.fr/ENG/Classification/index.php 
[5] Directive 2004/107/EC of the European Parliament and of the Council of 15 December 2004 relating to arsenic, cadmium, mercury, nickel and polycyclic aromatic hydrocarbons in ambient air

[6] F. Rolle, V. Maurino, M. Sega - "Metrological traceability for benzo[a]pyrene quantification in airborne particulate matter", Accreditation and Quality Assurance, Vol. 17, n. 2, 2012, pp. 191-197
[7] EN 15549:2008 - "Air Quality - Standard method for the measurement of the concentration of benzo[a]pyrene in ambient air"

[8] Directive 2008/50/EC of the European Parliament and of the Council of 21 May 2008 on ambient air quality and cleaner air for Europe

[9] US EPA Method 3540c "Soxhlet extraction" (1996). 